\title{
Novel Septoria Speckled Leaf Blotch Resistance Loci in a Barley Doubled-Haploid Population
}

\author{
Doris Luckert, Hala Toubia-Rahme, Brian J. Steffenson, Thin-Meiw Choo, and Stephen J. Molnar
}

First, fourth, and fifth authors: Eastern Cereal and Oilseed Research Centre, Agriculture and Agri-Food Canada, 960 Carling Ave., Ottawa, Ontario, K1A 0C6, Canada; second author: Animal and Plant Health Inspection Services, Boltzmanngasse 16, 1090 Vienna, Austria; and third author: Department of Plant Pathology, University of Minnesota, 495 Borlaug Hall, 1991 Upper Buford Circle, St. Paul 55108-6030. Accepted for publication 13 March 2012.

\begin{abstract}
Luckert, D., Toubia-Rahme, H., Steffenson, B. J., Choo, T.-M., and Molnar, S. J. 2012. Novel Septoria speckled leaf blotch resistance loci in a barley doubled-haploid population. Phytopathology 102:683-691.

The genetics of resistance to Septoria speckled leaf blotch (SSLB), caused by Septoria passerinii, was studied in the Leger $\times$ Clho9831 barley doubled-haploid population. The 140 lines in the population segregated as 102 resistant and 38 susceptible, approximating a 3:1 ratio. A recombination map was developed using diversity arrays technology and other molecular markers. Quantitative trait locus (QTL) analysis demonstrated that resistance is primarily conferred either by having the

CIho9831 allele at a QTL on 6HS or by having the CIho9831 allele at both of two QTLs on $3 \mathrm{H}$ and $2 \mathrm{HL}$. In addition, $\approx 1 / 16$ of the lines were resistant for unidentified reasons. This model predicts a resistant/susceptible ratio of 11:5, which fits the phenotypic observations. Minor QTLs were detected on 2HS and 1H. DNA sequences of linked markers suggest that the $6 \mathrm{HS}, 3 \mathrm{H}$, and $2 \mathrm{HS}$ QTLs are part of resistance gene clusters and that the 6HS and 3H QTLs share homology. The 6HS QTL is identical to or closely linked to the SSLB resistance locus Rsp4 and the $1 \mathrm{H}$ QTL to the $R s p 2$ or $R s p 3$ locus. The $3 \mathrm{H}$ and $2 \mathrm{HS}$ QTLs are unique and offer new opportunities for pyramiding resistance genes through marker-assisted breeding for resistance to $S$. passerinii.
\end{abstract}

Septoria speckled leaf blotch (SSLB), caused by the fungus Septoria passerinii Sacc., has reemerged as a major disease of barley (Hordeum vulgare L.) in the Upper Midwest region of the United States and in the Canadian Prairie Provinces (22). The disease remains a serious problem (28) because most of the malting and feed barley varieties grown in North America are susceptible (31). The most effective response to this challenge is the development of cultivars with genetic resistance. Several sources of resistance to $S$. passerinii have been identified in cultivated barley as well as in wild barley accessions (31). Identifying unique sources of resistance is facilitated by the observation that there is a strong correlation between adult resistance in the field and seedling resistance in the greenhouse or growth cabinet (31).

Breeding barley for resistance would also be facilitated by knowledge of the number and chromosomal locations of resistance genes in these unique sources and by the identification of associated molecular markers that could be used for molecular marker-assisted selection (MAS) breeding. Various restriction fragment length polymorphism (RFLP), random amplified polymorphic DNA (RAPD), simple sequence repeat (SSR), amplified fragment length polymorphism (AFLP), and diversity arrays technology (DArT) markers have been linked to the Rsp 1, Rsp2, and $R s p 3$ resistance genes. Rsp 1 was shown to map to barley chromosome $3 \mathrm{HS}$ and Rsp 2 and Rsp3 to two closely linked loci on 1HS (18,36). A sequence-characterized amplified region (SCAR) marker was developed for $R s p 2$ and $R s p 3$ (36) and sequence-

Corresponding author: S. J. Molnar; E-mail address: steve.molnar@agr.gc.ca

* The $\boldsymbol{e}$-Xtra logo stands for "electronic extra" and indicates that the online version contains one supplemental table.

ECORC Publication number 11-287.

http://dx.doi.org/10.1094/PHYTO-06-11-0181

(C) Her Majesty the Queen in Right of Canada, as represented by the Minister of Agriculture and Agri-Food Canada. tagged site (STS) markers linked to the three resistance loci have been developed for MAS breeding purposes (19). Recently, a new resistance locus, $R s p 4$, was mapped to chromosome $6 \mathrm{H}$ (28) and a novel resistance quantitative trait locus (QTL), $\mathrm{QrSp}-2 \mathrm{H}$, to $2 \mathrm{HL}$ (34). Resistance loci from the wild species $H$. vulgare subsp. spontaneum $\mathrm{C}$. Koch and $H$. bulbosum $\mathrm{L}$. have been mapped to $2 \mathrm{H}$ and $6 \mathrm{H}(35)$ and to $4 \mathrm{H}(30)$, respectively. To date, five resistance loci have been mapped in barley and three others have been identified in related Hordeum spp. It is probable that other resistance loci await discovery.

'CIho9831' is resistant to $S$. passerinii at both the seedling and adult stages (31). CIho9831 has been tested with STS markers and found to be positive for one of two markers developed for $R s p 1$, negative for both markers developed for $R s p 2$, and negative for the single marker developed for Rsp3 (19). These results showed that CIho9831 may or may not carry Rsp 1 but is unlikely to carry $R s p 2$ or $R s p 3$. However, the results must be interpreted with caution because the authors found that, although the Rsp3associated marker was highly diagnostic across a range of germplasm, the other STS markers were much less predictive. Thus, it is unclear whether CIho9831 contains a combination of recognized resistance genes or one or more novel resistance genes.

A doubled-haploid ( $\mathrm{DH}$ ) population has been developed from a cross between 'Leger' (a six-rowed Canadian barley cultivar susceptible to SSLB) and CIho9831. This population has already been characterized for resistance to net blotch $(13,23)$ and $\mathrm{Fu}$ sarium head blight (6) as well as for other traits, including kernel size and shape (10), chemical composition (9), salt tolerance (21), and agronomic traits $(15,32)$.

The objective of the present study was to use SSLB phenotype and molecular marker mapping data to characterize a $\mathrm{DH}$ population derived from the cross Leger $\times$ CIho9831 in order to determine the number of loci contributing to the resistance of CIho9831 to SSLB, their chromosomal locations, and whether these loci are unique or correspond to known resistance genes. 


\section{MATERIALS AND METHODS}

Germplasm and subpopulations. Leger is an elite, highyielding, six-rowed spring barley cultivar well adapted to Eastern Canada (8). CIho9831 is a two-rowed barley (GRIN database, United States Department of Agriculture-Agricultural Research Service; www.ars-grin.gov). Leger was crossed with CIho9831 and $155 \mathrm{DHs}$ were developed using the $H$. bulbosum technique (5). As genotyping of the $\mathrm{DH}$ lines proceeded, it became apparent that the DH lines constituted three sets. The earliest and the latest produced DHs shared common CIho9831 (CI, male) alleles; however, the middle set of DHs had a different CI allele at some loci. All DHs had the same Leger (L) allele at all loci. Genotyping multiple Leger seed and multiple CIho9831 seed revealed that Leger was homogeneous but CIho9831 contained two genotypes. With reference to the mapping population, we will refer to the large subpopulation (LS), the small subpopulation (SS), and the whole population (WP), which is a composite of these two highly related half-sib populations.

Disease evaluations. The parents and the progeny population (consisting of $155 \mathrm{DH}$ lines) were tested for resistance to $S$. passerinii at the seedling stage in the greenhouse. Plant growth conditions, inoculum preparation, and inoculation methods were as described by Toubia-Rahme and Steffenson (30,31). Parental plants and plants from the DH lines were grown in plastic pots (10 by $10 \mathrm{~cm}$ ) filled with a commercial potting mixture $(3: 1$ peat moss/perlite) (number 1 Sunshine Mix; Fisons Horticulture, Inc., Vancouver, BC, Canada). Slow-release (14-14-14, N-P-K, 2 g/pot) and water-soluble (15-0-15, N-P-K, N rate of $536 \mathrm{ppm}$ ) fertilizers were added at the time of planting. Plants were grown in a greenhouse at $20 \pm 3^{\circ} \mathrm{C}$ with $14 \mathrm{~h}$ of supplemental lighting (230 to $270 \mu \mathrm{E} \mathrm{m}^{-1} \mathrm{~s}^{-1}$ supplied by $1,000-\mathrm{W}$ metal halide lights). Seedlings were inoculated with the $S$. passerinii isolate (ND97-15) 10 to 12 days after planting, when the second leaves were fully expanded. Inoculum production was conducted using the protocols described by Toubia-Rahme et al. $(30,31)$. Pycnidiospore suspension $\left(5 \times 10^{5}\right.$ pycnidiospores $\left./ \mathrm{ml}\right)$ was applied on seedlings at a rate of $\approx 0.5 \mathrm{ml} /$ plant, using an atomizer pressured by an air pump at $60 \mathrm{kPa}$. Inoculated seedlings were incubated at $21^{\circ} \mathrm{C}$ in the dark and $25^{\circ} \mathrm{C}$ in the light for $72 \mathrm{~h}$ in chambers maintained near-saturation by periodic misting with ultrasonic humidifiers. The first $40 \mathrm{~h}$ of incubation were in darkness, followed by a photoperiod of $5 \mathrm{~h}\left(150\right.$ to $\left.270 \mu \mathrm{E} \mathrm{m}^{-1} \mathrm{~s}^{-2}\right)$, a dark period of $22 \mathrm{~h}$, and a photoperiod of $5 \mathrm{~h}$. Plants were allowed to dry off slowly before being transferred to the greenhouse under the same conditions previously described. In addition to routine watering, plants were misted twice a day to enhance infection and production of pycnidia. Infection responses (IRs) were assessed on the second leaves of seedlings 20 days after inoculation using a 0 -to-5 rating scale, where $0,1,2$, and combinations thereof were considered indicative of resistance and 3, 4, 5, and combinations thereof were considered indicative of susceptibility (31). Lines that exhibited yellowing but no or few pycnidia were scored as resistant. Resistant ('Atlas', plant introduction [PI] 539108) and susceptible ('Betzes', PI 129430) checks were included in all experiments. The experiment was repeated twice.

Genotyping with molecular markers and construction of recombination map. Genomic DNA was extracted from young leaves using the cesium chloride technique, as described previously (23), or with the Dellaporta method (7). The population was genotyped with DArT markers by Triticarte (www.triticarte.com.au), a subsidiary of Diversity Arrays Pty Ltd. (www.diversityarrays.com). In an effort to obtain many markers polymorphic across the WP, the array (version 1.7) containing DArT markers polymorphic in Australian and European germplasm as well as in wild barley accessions was used. Six parental samples and $88 \mathrm{DH}$ lines were genotyped using a 96 well plate with two blank control wells.
Data were analyzed for $87 \mathrm{DH}$ lines, consisting of 57 lines from the LS and 30 lines from the SS.

The initial DArT marker map was built using 496 DArT markers, which were polymorphic across the WP, showed normal segregation, and had both a quality score and a call rate above $80 \%$, as recommended by Triticarte and by Wenzl et al. (33). The map was constructed using Mapmaker v. 2.0 (16) for the Apple MacIntosh computer by grouping the markers at increasing logarithm of the odds (LOD) values (LOD 3.0 to 10.0, $\theta=0.40$ ), ordering them using the "Compare" and "Try" commands, testing marker order using the "Ripple" command, and then mapping using the Kosambi mapping function. For coincident markers, the marker with the highest LOD score was retained.

The DArT map was enhanced with 37 additional molecular markers and 2 morphological markers to fill gaps, improve resolution in specific regions, or cross-reference other studies. RAPD markers were employed as in Molnar et al. (23) and the morphological markers have been reported by Choo et al. (5). STS markers from A. Graner and T. Blake were used as described by Graner et al. (11) and Larson et al. (17), respectively. Polymerase chain reaction (PCR) products were separated on $2 \%$ agarose gels or 5\% Nusieve gels and stained with ethidium bromide. PCR conditions for SSR markers were the same as those described previously $(2,20,26)$ and SSR PCR products were then separated on a $6 \%$ denaturing polyacrylamide gel and silver stained according to Bassam and Caetano-Anolles (1). AFLP markers were generated by following the manufacturer's instructions (Gibco/ BRL/Invitrogen), which included labeling fragments with $\mathrm{P}^{33}$, separation on $6 \%$ polyacrylamide gel, and exposure to X-ray film.

QTL analysis. First, a correlation analysis was performed between the phenotypic data and each individual marker using the NQTL computer program (formerly named MQTL) (29). In all, 10,000 permutations of the data were used to calculate the threshold value, which must be exceeded by the test statistic (TS) to declare a QTL to be significant. To search for additive or epistatic interactions, the peak marker for the strongest QTL was fixed and the full marker dataset reanalyzed to identify markers giving strong correlation.

Second, the recombination map was used for simplified interval mapping (SIM) QTL analysis performed with NQTL. The phenotypic trait means of each DH line were analyzed with an experiment-wide error rate of 5\%. As before, 10,000 permutations were used to calculate the threshold. Regions with a TS above the threshold were considered a QTL. The major QTL was then anchored and the map was rescanned for regions that had additive or epistatic effects.

Third, simplified composite interval mapping (sCIM) was done on the recombination map using 14 background markers, 2 per chromosome. Analysis parameters were 10,000 permutations, $5 \%$ error rate, and a walking speed of 5 centimorgans $(\mathrm{cM})$.

The DNA sequences of many of the DArT markers are available from Diversity Arrays Pty. Ltd. (http://www.diversityarrays. com/sequences.html) and were used to annotate markers near each QTL using BLASTN, available on the National Center for Biotechnology Information (NCBI) website (http://www.ncbi. nlm.nih.gov/).

\section{RESULTS}

Disease assessment. The parents Leger and CIho9831 exhibited a clear differential reaction to $S$. passerinii. Leger was susceptible (IR of 4 to 5), whereas CIho9831 was highly resistant (IR of 0 ). Of the $155 \mathrm{DH}$ lines tested, 13 lines exhibited different reactions between the two experiments and were omitted. Two additional lines were assessed on just a single plant and were also omitted from the calculation of the segregation ratio. The remaining 140 homozygous DH lines exhibited a ratio of resistant/susceptible (R/S) of 102:38 (2 lines with IR of 2.5 scored as 
S) (Fig. 1). This segregation ratio fits a 3:1 ratio $\left(\chi^{2}=0.343, P=\right.$ 0.56 , df $=1)$, suggesting that the resistance of CIho9831 to $S$. passerinii could be governed by two independently segregating genes, either one of which confers resistance.

DArT marker map. High-quality DArT markers were used to construct a recombination map of the whole Leger $\times$ CIho9831 population (Fig. 2). In total, 1,083 DArT markers were screened and 496 were polymorphic across the WP, of which 334 had known map locations. Because many DArT markers co-mapped, only the one with the highest LOD score was retained during the map-building process. Complete linkage groups were obtained corresponding to chromosomes $2 \mathrm{H}, 5 \mathrm{H}, 6 \mathrm{H}$, and $7 \mathrm{H}$. In the case of chromosomes $3 \mathrm{H}$ and $4 \mathrm{H}$, the WP DArT markers fell into three small linkage groups, which were easily joined by the addition of a few non-DArT markers. A similar situation arose on chromosome $1 \mathrm{H}$, where mapping the WP DArTs left two large gaps, which were easily filled with either WP non-DArT markers or subpopulation-specific DArT markers. Both versions of $1 \mathrm{H}$ are shown in Figure 2; the first version was used for the QTL analysis and the second version facilitates convenient comparison to the DArT consensus map. The two versions of the final full map include 163 (with $1 \mathrm{H}$ map) or 180 (with $1 \mathrm{H}^{*}$ map) DArT markers. The final map also includes 37 non-DArT molecular markers and two morphological markers (row number, lemma color). Total length of the map is $1,246 \mathrm{cM}$, highly consistent with the $1,161 \mathrm{cM}$ of the DArT consensus map (33) and other published studies.

The Leger $\times$ CIho9831 map was almost identical to the published barley DArT consensus map (33), with a few exceptions (Supplemental Table 1). Each difference was individually tested and, in all cases, for the present data, the marker order shown on this population's DArT map was preferred over the consensus order with respect to LOD values and length of the linkage group. Most differences were simple flips in marker order for tightly linked markers, and such differences are often observed in recombination mapping. In addition, three more DArT markers mapped to different chromosomes on the present map than on the consensus map. Based on the low frequency of such observations and the high quality of the data, it is possible that these are members of duplicated loci.

QTL analysis of SSLB phenotype data. The results of QTL analysis for resistance to SSLB are summarized in Figures 2 and 3 and Tables 1 and 2. Although QTL analysis was performed for all 36 combinations of disease rating (experiments 1,2, and mean) by the three populations (WP, LS, and SS) by four QTL techniques (SIM, sCIM, additive, and epistatic), to be conservative in the analysis, only those combinations that detected a QTL (i.e., a TS above threshold) using the mean disease rating data are listed in Tables 1 and 2.

QTL analysis consistently showed a major QTL on the short arm of chromosome $6 \mathrm{H}$ at the AFLP marker E35616, and close to DArT markers bPb-7165 and bPb-5252 and SSR marker BMAG500 (Table 1; Figs. 2 and 3A and B). Experiment 1 data had a higher TS than experiment 2 and explained more of the phenotypic variation than experiment 2 (62 compared with 53\%) (data not shown). This QTL was detected in the WP (61\%) as well as in both the LS (61 to 64\%) and the SS (58\%) by using both SIM and sCIM. The CI allele from CIho9831 increased resistance to $S$. passerinii and this was reflected by a decrease in disease rating of 1.87 to 2.78 units, on a scale of 0 to 5 (Table 1 ).

A second large-effect QTL was identified on chromosome $3 \mathrm{H}$ by $\mathrm{SCIM}$ in the WP and by testing in the WP and in the LS for epistatic or additive interactions with the chromosome $6 \mathrm{H}$ QTL (Tables 1 and 2; Figs. 2 and 3B to D). The QTL peaked near one of four closely linked markers (UMB301, bPb-3025, bPb-2018, and ABG070), depending on the particular analysis. It explains $12 \%$ of the phenotypic variation, and the CI allele at this locus decreased the IR by 1.17 . The combination of the chromosome
$6 \mathrm{H}$ and $3 \mathrm{H}$ QTLs explained, in total, 70\% of the phenotypic variation. For lines that have the $\mathrm{CI}$ allele at the chromosome $6 \mathrm{H}$ locus, having the $\mathrm{CI}$ allele at the chromosome $3 \mathrm{H}$ locus increases resistance to SSLB and reduces the IR by 2.32 to 2.36 units.

Two smaller QTLs were detected on opposite arms of chromosome $2 \mathrm{H}$ by testing for epistatic effects when the main QTL on $6 \mathrm{H}$ was used as a cofactor (Table 2; Figs. 2 and 3D). This first QTL on 2HS peaked at DArT marker bPb-1212, depending on the particular analysis; the peak of the second QTL on 2HL is located at one of the tightly linked DArT markers bPb-8117, bPb-5755, and $\mathrm{bPb}-2971$. For lines that have the $\mathrm{CI}$ allele at the $6 \mathrm{H}$ QTL, having CI alleles at these two QTLs increases resistance to SSLB and decreases the IR by 1.62 and 1.76 to 2.81 units, respectively. The combination of $6 \mathrm{H}, 3 \mathrm{H}, 2 \mathrm{HL}$, and $2 \mathrm{HS}$ QTLs explains $74 \%$ of the phenotypic variation.

Consideration of the epistatic interaction between the 6H QTL and either the $3 \mathrm{H}, 2 \mathrm{HS}$, or $2 \mathrm{HL}$ QTL suggests that the CI/CI and $\mathrm{CI} / \mathrm{L}$ predicted genotypic classes have similar IR values (Table 2 ). As a result in each pairing, only three IR phenotypes are observed, indicating that the $6 \mathrm{H}$ QTL exhibits dominant epistasis over the other three QTL.

In the present barley population, a minor QTL with epistatic effects was detected on the short arm of chromosome $1 \mathrm{H}$ near DArT markers bPt-0005 (7.2 cM) and bPb-5877, but only in the SS. For lines that have the L allele at the $6 \mathrm{H}$ QTL, having the CI allele at the 1H QTL unexpectedly and dramatically decreased resistance and increased IR by 3.94 units (Table 2). In the Leger $\times$ CI9831 population, DArT marker bPt-0005 co-maps with SCAR marker E-ACT/M-CAA-170a (data not shown), developed by Zhong et al. (36) for selecting the Rsp2 SSLB resistance allele. In addition, this QTL is in the region of the hor2 hordein locus.

Analysis of genotypic classes. To better understand the role of each of these five QTLs in generating the resistance phenotype, the different genotypic classes were examined and a subset presented in Table 3. Approximately half of the lines in the population have the CI allele at the peak marker for the 6H QTL and mixed alleles (m) at the other four QTLs (genotype Rmmmm) and all are resistant, indicating that the $6 \mathrm{H}$ QTL is a single major resistance gene. There is relatively little effect on IR of having resistance alleles at the other four QTLs for lines that already have the CI resistance allele at the 6H QTL. The other half of the population is composed of lines having the L susceptibility allele at the 6H QTL (Smmmm), and these are mixed for both resistance and susceptibility. For these lines, if one also considers their genotype at the peak marker for the $3 \mathrm{H}$ QTL, then those with the $\mathrm{L}$ allele $(\mathrm{SSmmm})$ are all susceptible but those with the CI allele (SRmmm) are mixed. The similar situation holds true for the $2 \mathrm{HL}$

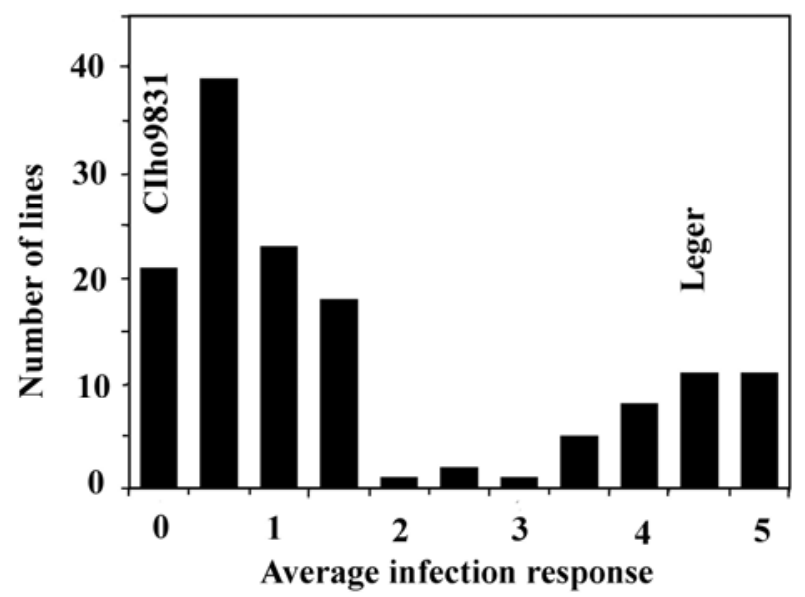

Fig. 1. Histogram of the Septoria infection response rating of 140 doubledhaploid lines from the Leger $\times$ CIho9831 population relative to parental averages. 

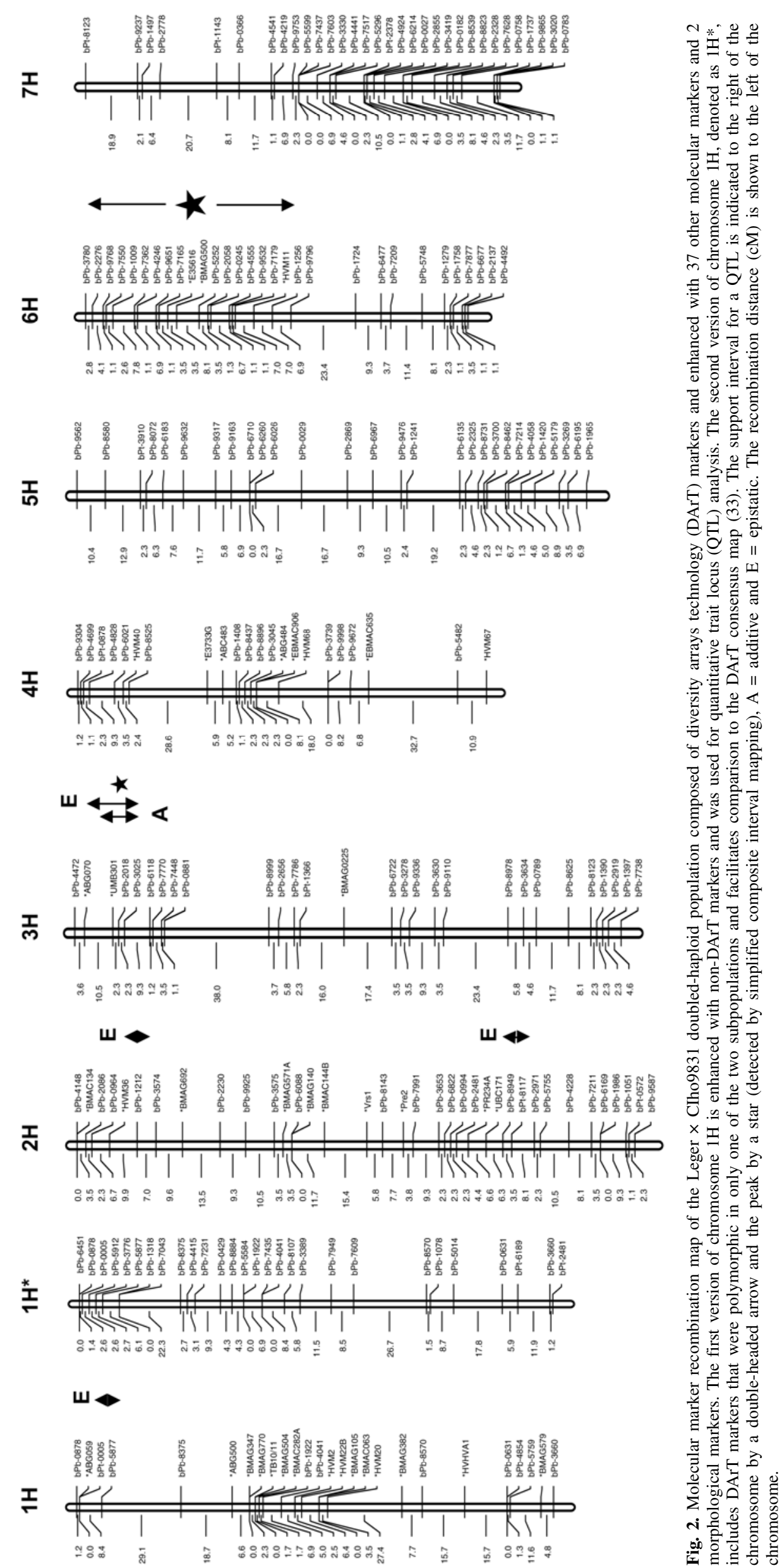
QTL, where most (R/S, 1:11) of those with the L allele (SmSmm) are susceptible but those with the CI allele $(\mathrm{SmRmm})$ are mixed. The impact of the $3 \mathrm{H}$ QTL on IR $(3.09-1.99=1.1)$ (Table 3) is also very similar to that of the $2 \mathrm{HL}$ QTL $(3.09-2.1=0.99)$, by this analysis. Eight of nine lines having $\mathrm{CI}$ alleles at both the $3 \mathrm{H}$ and 2HL QTLs (SRRmm) are resistant. The nine lines have an average IR of 0.95 , very close to that predicted for an additive interaction between the $3 \mathrm{H}$ and $2 \mathrm{HL}$ QTLs $(3.09-1.1-0.99=$ 1.0). Similarly, the $2 \mathrm{HS}$ QTL appears additive with $3 \mathrm{H}$ and $2 \mathrm{HL}$ QTLs but with smaller impact on IR. To address the latter two points, the WP was divided into two halves, based on lines having the L or CI allele at the major 6H QTL, and then QTL analysis was performed independently in each half. No additional QTL were detected in the half of the population with the CI allele at the $6 \mathrm{H}$ QTL. In the half of the population having the $\mathrm{L}$ allele at the

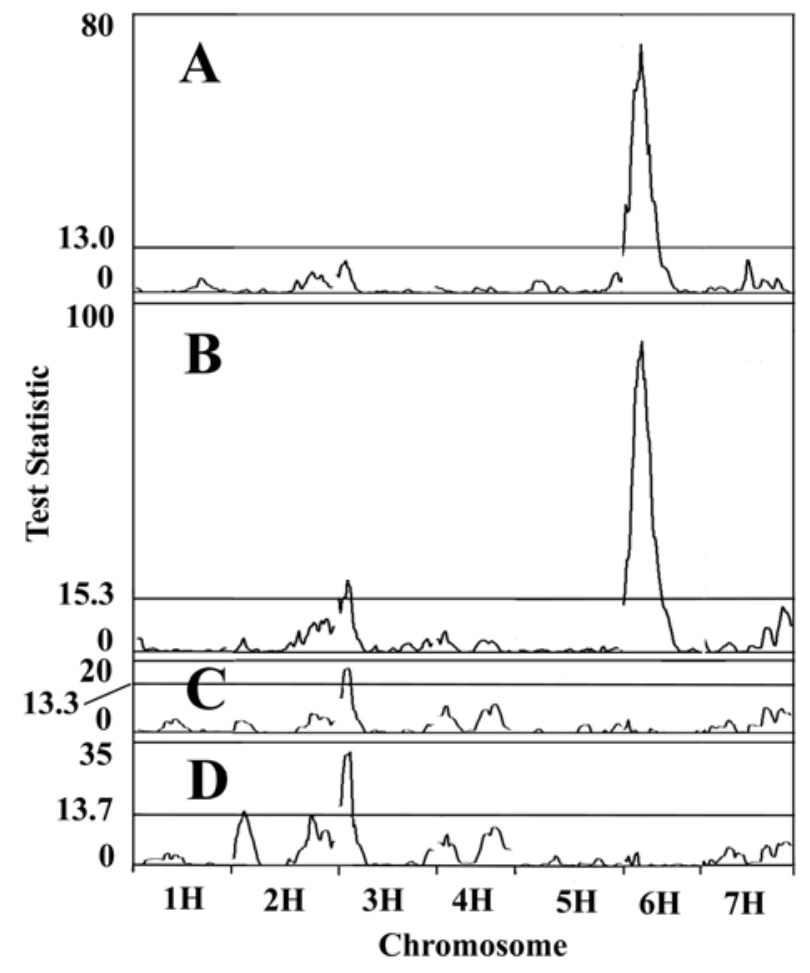

Fig. 3. Quantitative trait loci (QTLs) probability scans showing the variation in test statistic (TS) along the maps of the seven chromosomes. Results are shown for analyses in the whole population using the following: A, simplified interval mapping; B, simplified composite interval mapping; $\mathbf{C}$, additive interaction with the 6H QTL; and D, epistatic interaction with the 6H QTL. Horizontal lines show the respective TS thresholds for declaring a QTL.
6H QTL, QTL analysis detected both the $3 \mathrm{H}$ and the 2HL QTLs, and they were strongly epistatic (data not shown). It would appear that there are at least two classes of resistant lines. The first consists of lines having the CI allele at the 6H QTL (Rmmmm) and the second of those that have the L allele at the $6 \mathrm{H}$ QTL but have CI alleles at both the $3 \mathrm{H}$ and 2HL QTLs (SRRmm) and, ideally, also at the 2HS QTL (SRRRm). All other genotypic classes at the $6 \mathrm{H}, 3 \mathrm{H}, 2 \mathrm{HL}$, and $2 \mathrm{HS}$ loci are susceptible or a mix of resistant and susceptible. One-half and one-eighth of the DH lines are expected to have the Rmmmm and SRRmm genotypes, respectively, and be resistant. However, these two genotypes do not account for all the resistant lines. There are 12 resistant lines plus 23 susceptible lines plus 3 lines which scored resistant in one experiment and susceptible in the other experiment within the Smmmm half of the population, and 8 of these resistant lines have the SRRmm genotype. The remaining four resistant lines are resistant due to one or more unidentified factors. Because eight resistant lines have genotype SRRmm, which is expected in 1/8 of DH lines in a balanced population, we can estimate that the mechanisms responsible for the additional four resistant lines would be expected in $\approx 1 / 16$ of the $\mathrm{DH}$ lines. A complex genetic model (three loci or two genotypes + unidentified factor) gives an expected R/S ratio of 11:5, which is not significantly different from the observed R/S ratio of 102:38 $\left(\chi^{2}\right.$ value $=1.099, P=0.2944$, $\mathrm{df}=1)$.

Genic environment of the chromosome $6 \mathrm{H}$ and $3 \mathrm{H}$ QTLs. The DNA sequences of several of the DArT markers mapped in Leger $\times$ CIho9831 and linked to the $3 \mathrm{H}$ and $6 \mathrm{H}$ QTLs are available on the Diversity Arrays Pty. Ltd. website. Additional sequenced DArT markers mapping to these two genomic regions are identified on the DArT consensus map (33). The sequences of such DArT markers were screened by BLASTN analysis against the NCBI nucleotide database.

The closest DArT marker to the peak of the $6 \mathrm{H} \mathrm{QTL}$ is bPb7165 , which has homology to a wheat chromosome 3B-specific BAC clone containing an $H v-p g 4$ homolog and HGA-like sequences. Those $H v$-pg 4 and HGA-like sequences have homologs at the barley leaf rust resistance Rph7 multigenic locus (Table 4). Co-mapping DArT markers bPb-8398 and bPb-8492 have high homology to the barley stem rust resistance gene Rpgl and the wheat leaf rust resistance gene $L r l$, respectively. Other closely linked DArT markers (bPb-9749 and bPb-9807) also have homologies to various disease resistance genes (Table 4). This observation suggests that the $6 \mathrm{H}$ QTL and the previously reported Rsp4 locus, which maps to the same region, are members of a cluster of resistance genes and resistance gene analogs. Within this cluster, more detailed allelic or sequencing studies are required to determine whether the Leger $\times$ CIho9831 QTL and Rsp4 are allelic or at tightly linked loci.

TABLE 1. Map positions of quantitative trait loci (QTLs) detected by simple interval mapping (SIM), simplified composite interval mapping (sCIM), or additive interaction (Add) analysis and their effects detected for resistance to Septoria speckled leaf blotch in the Leger $\times$ CIho9831 doubled-haploid population

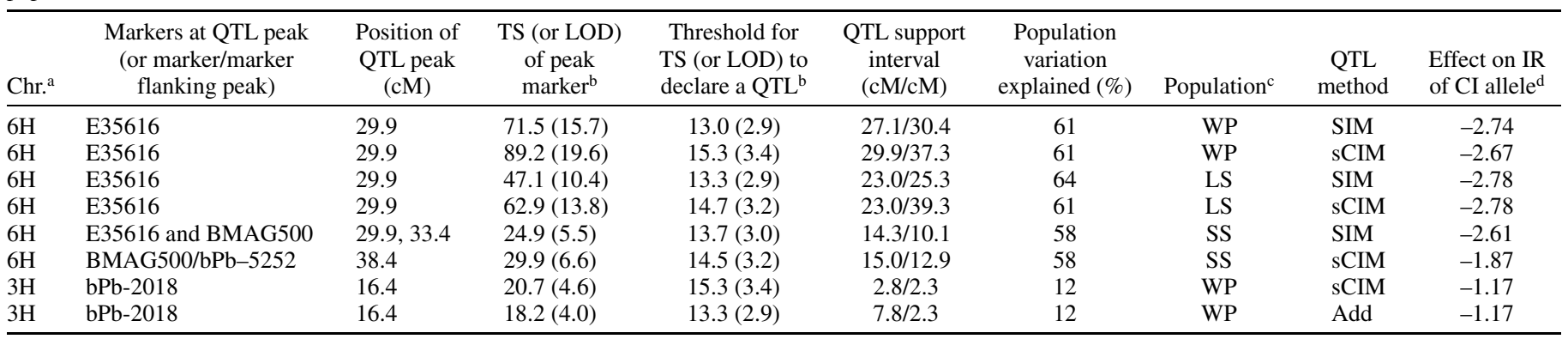

a Chromosome.

${ }^{\mathrm{b}}$ Logarithm of the odds (LOD) values estimated by multiplying the test statistic $(\mathrm{TS}) \times 0.22(29)$; cM = centimorgans

c QTL detection in whole population (WP) or in large (LS) or small (SS) subpopulation.

d $\mathrm{IR}=$ infection response and CI $=$ CIho9831 allele. 
One of the peak markers for the $3 \mathrm{H}$ QTL is $\mathrm{bPb}-3025$. The sequence of the co-mapping marker bPb-1137 is highly homologous to that of the 212-kb barley contig 211252, which spans the barley Rph7 leaf rust resistance locus and has been shown to contain four members of the HGA gene family and six other genes, including $H v-p g 4$ (4). The proximal flanking DArT marker bPt-1350 and the distal flanking SSR marker UMB301 both have homology to wheat leaf rust resistance kinases, suggesting that they are part of a disease resistance cluster at this genomic region.

\section{DISCUSSION}

Subpopulations. This study showed an unexpected structure within the DH mapping population, which was easily detected because the $\mathrm{DH}$ lines were numbered in chronological order of their production. The origin of the two subpopulations could be traced to the use of two genotypes of the male parent CIho9831. This reinforces the desirability of using DH parents when developing a mapping population. However, this is seldom the case and, as a result, we expect that the present barley mapping population is not unique in having such structure. Because of the structure, extra care was required when analyzing the mapping and QTL data to ensure that population structure did not affect results. In the present study, the same QTLs were identified by using separate QTL analysis in each subpopulation and in the combined population, with a few minor exceptions, and analysis in the combined population was generally more robust. This is expected because most QTLs are in genomic regions in which the two subpopulations are indistinguishable.

Genetic models. Septoria IR rating of $140 \mathrm{DH}$ lines was largely bimodal (Fig. 1). The observed R/S ratio of 102:38 closely matched a 3:1 ratio. Qualitative genetic analysis suggested that two resistance loci might be responsible for resistance in the Leger $\times$ CIho9831 population. Quantitative genetic analysis suggested a more complex genetic model. A major QTL for resistance to SSLB was detected on chromosome 6HS and a second major QTL on $3 \mathrm{H}$. The combined additive effect of these genes explained $70 \%$ of the phenotypic variation. Several additional QTLs were also detected, the most important of which was on 2HL. Analysis of genotypic classes indicated that most resistant

TABLE 2. Quantitative trait loci (QTLs) (epistatic) map positions and their effects detected for resistance to Septoria speckled leaf blotch in the Leger $\times$ CIho9831 doubled-haploid population

\begin{tabular}{|c|c|c|c|c|c|c|c|c|c|c|c|}
\hline \multirow[b]{2}{*}{$\mathrm{Chr}^{\mathrm{a}}$} & \multirow[b]{2}{*}{ Marker at peak ${ }^{\mathrm{b}}$} & \multirow[b]{2}{*}{ Position $(\mathrm{cM})^{\mathrm{c}}$} & \multirow[b]{2}{*}{$\mathrm{TS}(\mathrm{LOD})^{\mathrm{d}}$} & \multirow[b]{2}{*}{ Threshold TS (LOD) $)^{\mathrm{d}, \mathrm{e}}$} & \multirow[b]{2}{*}{ Support $(\mathrm{cM})^{\mathrm{f}}$} & \multirow[b]{2}{*}{ Pop. ${ }^{g}$} & \multicolumn{4}{|c|}{ IR scores ${ }^{\mathrm{h}}$} & \multirow[b]{2}{*}{ Effect $^{\mathrm{i}}$} \\
\hline & & & & & & & $\mathrm{CI} / \mathrm{CI}$ & $\mathrm{CI} / \mathrm{L}$ & $\mathrm{L} / \mathrm{CI}$ & $\mathrm{L} / \mathrm{L}$ & \\
\hline $3 \mathrm{H}$ & bPb-3025 & 18.7 & $32.2(7.1)$ & $13.7(3.0)$ & $4.9 / 5.0$ & WP & 0.55 & 0.62 & 2.19 & 4.55 & -2.36 \\
\hline $3 \mathrm{H}$ & ABG070/UMB301 & 8.6 & $21.0(4.6)$ & $20.2(4.4)$ & $0 / 10.1$ & LS & 0.74 & 0.69 & 2.33 & 4.65 & -2.32 \\
\hline $2 \mathrm{HL}$ & bPb-8117/bPb-2971 & 165.7 & $14.3(3.2)$ & $13.7(3.0)$ & $0 / 0$ & WP & 0.62 & 0.54 & 2.32 & 4.08 & -1.76 \\
\hline $2 \mathrm{HL}$ & bPb-8117 & 160.7 & $19.6(4.3)$ & $16.9(3.7)$ & $27.7 / 0$ & SS & 0.43 & 0.36 & 1.31 & 4.12 & -2.81 \\
\hline $1 \mathrm{H}$ & bPt-0005/bPb-5877 & 6.2 & $18.0(4.0)$ & $16.9(3.7)$ & $5.0 / 0$ & SS & 0.44 & 0.32 & 3.94 & 0 & 3.94 \\
\hline
\end{tabular}

${ }^{a}$ Chromosome.

${ }^{\mathrm{b}}$ Marker at QTL peak (or marker/marker flanking peak).

${ }^{\mathrm{c}}$ Position of QTL peak; cM = centimorgans.

${ }^{\mathrm{d}}$ Logarithm of the odds (LOD) values estimated by multiplying the test statistic $(\mathrm{TS}) \times 0.22(29)$.

e Threshold for TS (or LOD) to declare a QTL.

${ }^{\mathrm{f}}$ QTL support interval $(\mathrm{cM} / \mathrm{cM})$.

$\mathrm{g}$ QTL detection in whole population (WP) or in large (LS) or small (SS) subpopulation.

${ }^{\mathrm{h}}$ Infection response (IR) scores of genotypic classes for epistasis between 6H QTL and tested QTL. Allele designations are Leger (L) and CIho9831 (CI).

${ }^{\mathrm{i}}$ Effect on IR of $\mathrm{CI}$ at test locus.

TABLE 3. Genotypic classes, Infection response (IR) of class, and distribution of lines per class

\begin{tabular}{|c|c|c|c|c|c|c|c|c|c|c|c|}
\hline \multirow{2}{*}{\multicolumn{5}{|c|}{ Genotypic classes at QTL ${ }^{\mathrm{a}}$}} & \multicolumn{7}{|c|}{ IR, class phenotypes, and ratio of lines ${ }^{b, c}$} \\
\hline & & & & & \multicolumn{2}{|c|}{ Whole population } & \multicolumn{2}{|c|}{ Large subpopulation } & \multicolumn{2}{|c|}{ Small subpopulation } & \multirow{2}{*}{$\begin{array}{c}\text { Overall } \\
\text { Phenotype }\end{array}$} \\
\hline $6 \mathrm{H}$ & $3 \mathrm{H}$ & $2 \mathrm{HL}$ & $2 \mathrm{HS}$ & $1 \mathrm{H}$ & IR & Phenotype & IR & Phenotype & IR & Phenotype & \\
\hline $\mathrm{R}$ & $\mathrm{R}$ & $\ldots$ & $\ldots$ & $\ldots$ & 0.53 & $R(22 R)$ & 0.69 & $\mathrm{R}(11 \mathrm{R})$ & 0.36 & $\mathrm{R}(11 \mathrm{R})$ & $\mathrm{R}$ \\
\hline $\mathrm{R}$ & $\mathrm{R}$ & $\mathrm{R}$ & $\ldots$ & $\ldots$ & 1.08 & $\mathrm{R}(10 \mathrm{R})$ & 0.64 & $\mathrm{R}(6 \mathrm{R})$ & 0.43 & $\mathrm{R}(4 \mathrm{R})$ & $\mathrm{R}$ \\
\hline $\mathrm{R}$ & $\mathrm{R}$ & $\mathrm{R}$ & $\mathrm{R}$ & $\ldots$ & 0.83 & $\mathrm{R}(6 \mathrm{R})$ & 0.90 & $\mathrm{R}(5 \mathrm{R})$ & 0.50 & $R(1 R)$ & $\mathrm{R}$ \\
\hline $\mathrm{R}$ & $\mathrm{R}$ & $\mathrm{R}$ & $\mathrm{R}$ & $\mathrm{R}$ & 1.03 & $\mathrm{R}(4 \mathrm{R})$ & 1.03 & $\mathrm{R}(4 \mathrm{R})$ & - & nil & $\mathrm{R}$ \\
\hline $\mathrm{S}$ & $\ldots$ & $\mathrm{S}$ & $\ldots$ & $\ldots$ & 4.05 & $\mathrm{M}(1 \mathrm{R}, 1 \mathrm{R} / \mathrm{S}, 11 \mathrm{~S})$ & 4.13 & $\mathrm{M}(1 \mathrm{R}, 1 \mathrm{R} / \mathrm{S}, 7 \mathrm{~S})$ & 3.89 & $S(4 S)$ & $\mathrm{M} / \mathrm{S}$ \\
\hline $\mathrm{S}$ & $\ldots$ & $\ldots$ & $\ldots$ & $\ldots$ & 3.09 & $M(12 R, 3 R / S, 23 S)$ & 3.26 & $\mathrm{M}(8 \mathrm{R}, 3 \mathrm{R} / \mathrm{S}, 16 \mathrm{~S})$ & 2.74 & $M(4 R, 7 S)$ & $\mathrm{M}$ \\
\hline S & $\mathrm{R}$ & $\ldots$ & $\ldots$ & $\ldots$ & 1.99 & $M(12 R, 3 R / S, 9 S)$ & 2.04 & $\mathrm{M}(8 \mathrm{R}, 3 \mathrm{R} / \mathrm{S}, 7 \mathrm{~S})$ & 1.51 & $\mathrm{M}(4 \mathrm{R}, 2 \mathrm{~S})$ & M \\
\hline $\mathrm{S}$ & $\ldots$ & $\mathrm{R}$ & $\ldots$ & $\ldots$ & 2.10 & $\mathrm{M}(8 \mathrm{R}, 5 \mathrm{~S})$ & 2.69 & $\mathrm{M}(4 \mathrm{R}, 4 \mathrm{~S})$ & 1.15 & $\mathrm{M}(4 \mathrm{R}, 1 \mathrm{~S})$ & M \\
\hline $\mathrm{S}$ & $\ldots$ & $\ldots$ & $\mathrm{R}$ & $\ldots$ & 2.51 & $\mathrm{M}(8 \mathrm{R}, 7 \mathrm{~S})$ & 2.98 & $\mathrm{M}(4 \mathrm{R}, 5 \mathrm{~S})$ & 1.67 & $\mathrm{M}(4 \mathrm{R}, 2 \mathrm{~S})$ & $\mathrm{M}$ \\
\hline $\mathrm{S}$ & $\ldots$ & $\ldots$ & $\ldots$ & $\mathrm{R}$ & 3.09 & $\mathrm{M}(5 \mathrm{R}, 1 \mathrm{R} / \mathrm{S}, 8 \mathrm{~S})$ & 3.88 & $\mathrm{M}(2 \mathrm{R}, 1 \mathrm{R} / \mathrm{S}, 7 \mathrm{~S})$ & 1.31 & $M(3 R, 1 S)$ & M \\
\hline $\mathrm{S}$ & $\mathrm{R}$ & $\mathrm{R}$ & $\cdots$ & $\ldots$ & 0.95 & $\mathrm{M}(8 \mathrm{R}, 1 \mathrm{~S})$ & 1.45 & $M(4 R, 1 S)$ & 0.44 & $\mathrm{R}(4 \mathrm{R})$ & $\mathrm{M} / \mathrm{R}$ \\
\hline $\mathrm{S}$ & $\mathrm{R}$ & $\mathrm{R}$ & $\mathrm{R}$ & $\ldots$ & 0.94 & $M(7 R, 1 S)$ & 1.44 & $\mathrm{R}(3 \mathrm{R}, 1 \mathrm{~S})$ & 0.44 & $\mathrm{R}(4 \mathrm{R})$ & $\mathrm{M} / \mathrm{R}$ \\
\hline
\end{tabular}

${ }^{a} \mathrm{R}$ alleles are contributed by CIho9831 at $6 \mathrm{H}, 3 \mathrm{H}, 2 \mathrm{HL}$, and $2 \mathrm{HS}$ quantitative trait loci (QTLs) and by Leger at the $1 \mathrm{H}$ QTL. S and ... (mixed) alleles at QTL are also indicated. Classes defined by QTL peak markers E35616 (6H), UMB301 (3H), bPb-8117 (2HL), bPb-1212 (2HS), and bPt-0005 (1H).

${ }^{\mathrm{b}}$ Class phenotypes: resistant (R), susceptible (S), or mixed (M).

${ }^{c}$ Doubled-haploid lines that scored as R on one pathology test and $\mathrm{S}$ on the other are noted as R/S but were excluded from the calculation of the average IR for that genotypic class. -, not applicable. 
lines either had the CI allele at the 6HS QTL or had CI alleles at both the $3 \mathrm{H}$ and $2 \mathrm{HL}$ QTLs. In addition, $\approx 1 / 16$ of the DH lines in the population were resistant due to one or more unidentified factors. According to the resultant genetic model, 5/8 of the DH lines are resistant due to two genotypes generated at three loci, and an additional $1 / 16$ of the $\mathrm{DH}$ lines are resistant for unidentified reasons. Thus, the genetic model emerging from quantitative analysis plus analysis of genotypic classes differs from the genetic model suggested by qualitative genetic analysis. Both models fit the observed ratio of resistant and susceptible lines but only the more complex model also fits the QTL analysis and the analysis of genotypic classes.

Chromosome 6H QTL. An unnamed resistance locus from wild barley ( $H$. vulgare subsp. spontaneum) has been mapped to chromosome $6 \mathrm{H}$ bins 10 to 14 (35). In cultivated barley, a different resistance locus, given the name $R s p 4$, has been mapped to chromosome $6 \mathrm{H}$ bins 3 to 4 by St. Pierre et al. (28). The resistance QTL on chromosome $6 \mathrm{H}$ identified in the present study is linked to DArT markers whose map locations, as shown on the consensus map of Wenzl et al. (33), overlap the DArT markers flanking $R s p 4$. Therefore, recombination mapping suggests that the QTL identified in the present study and the $R s p 4$ locus map very close to each other and may actually be the same locus, though perhaps carrying different resistance alleles. A more accurate assessment of map locations for Rsp4 and the Leger $\times$ CIho9831 QTL would require a much larger mapping population.

St. Pierre et al. (28) reported that their SSLB resistant parental line, Sep2-72, derived its $R s p 4$ resistance gene from the line Pc84. Pc-84 is a six-rowed breeding line developed at CIMMYT (GRIN accession PI 584764, NSGC accession 5543) and, based on pedigree, derives its SSLB resistance from a series of sister lines, Gloria-sib/Copal-sib (14,31). In contrast, CIho9831 is a two-rowed accession. Although it remains to be determined whether the 6H QTL identified in the present study is or is not the same locus as Rsp4, the level of resistance in the two lines is comparable because, in parallel testing, CIho9831 and Pc-84 scored IRs of 0 to 1 and 1, respectively (31). Further allelic studies are required to address this question, which will have implications for the utilization and perhaps pyramiding of these two resistance genes within barley breeding programs.

Disease resistance genes and resistance gene analogs are often organized into clusters, and it is possible that $R s p 4$ and the QTL identified in the present study are tightly linked within such a cluster. Evidence supporting the presence of a cluster includes the fact that many of the DArT markers mapping to this region have homology to disease resistance genes (Table 4) and that the same regions (bins 3 to 4 ) are known to carry other resistance genes for scald (27) and net blotch (28). Further, based on mutual tight linkage to SSR marker BMAG500, these two SSLB resistance loci are tightly linked to leaf rust resistance locus $R p h 13$ and resistance QTLs for powdery mildew (Rbg-2-5), leaf scald (Rrs-25), and net type net blotch (Rpt-4-5) (35).

Chromosome 3H QTL. The SSLB resistance gene Rsp 1 has been mapped to chromosome 3HS, distal to the DArT markers bPb-9945 and bPb-6978 (18). From this, the position of Rsp 1 on the DArT consensus map can be estimated as $31.8 \mathrm{cM}$. By comparison, eight DArT markers within the support interval of the QTL identified in the present study are located at map positions of 1.0 to $10.2 \mathrm{cM}$ on the DArT consensus map. Thus, the CIho9831 QTL identified in the present study appears to be a unique resistance locus well separated from Rsp 1 . This new SSLB resistance gene is located in a region of DArT markers with homology to several cereal rust resistance genes (Table 4), including $R p h 7$, as well as a net-type net blotch resistance QTL (Rpt-1-2) (35). It has potential for breeding barley for SSLB resistance.

Chromosome 2H QTLs. Two additional QTLs were detected on chromosome $2 \mathrm{H}$ at peak markers that map at $42.5 \mathrm{cM}$ on $2 \mathrm{HS}$ and at 123 to $133 \mathrm{cM}$ on $2 \mathrm{HL}$ on the DArT consensus map (33). These map positions are well separated from that of an SSLB resistance QTL (Rsp-7-11) identified in wild barley (H. vulgare subsp. spontaneum), which mapped to chromosome $2 \mathrm{H}$ and peaked distal to the SSR marker BMAG0518 (72.5 cM on

TABLE 4. Resistance genes and analogs linked to Septoria speckled leaf blotch resistance quantitative trait loci (QTLs)

\begin{tabular}{|c|c|c|c|c|c|}
\hline Chr. $^{\mathrm{a}}$ & $\begin{array}{l}\text { Present map } \\
(\mathrm{cM})^{\mathrm{b}}\end{array}$ & $\begin{array}{l}\text { Consensus map } \\
(\mathrm{cM})^{\mathrm{b}}\end{array}$ & Marker & Homologies identified by BLAST (\% base pair match) & $\begin{array}{c}\text { Accession number } \\
\text { of match }\end{array}$ \\
\hline $6 \mathrm{H}$ & 30.0 & 24.0 & BMAG500 & $\ldots$ & $\ldots$ \\
\hline $6 \mathrm{H}$ & $\ldots$ & 26.5 & bPb-8398 & Barley serine/threonine kinase-like protein (76) & DQ469713.1 \\
\hline $6 \mathrm{H}$ & $\ldots$ & 26.5 & bPb-8398 & Pseudogene of barley stem rust resistance gene Rpgl (70) & AF509765.1 \\
\hline $6 \mathrm{H}$ & $\ldots$ & 26.5 & bPb-8492 & Wheat calmodulin (71) & U48691.1 \\
\hline $6 \mathrm{H}$ & $\ldots$ & 26.5 & bPb-8492 & Wheat leaf rust resistance gene $\operatorname{Lrl}$ (69) & EF567062.1 \\
\hline $6 \mathrm{H}$ & $\ldots$ & 26.5 & bPb-8492 & Wheat malate dehydrogenase (68) & EF109239.1 \\
\hline $6 \mathrm{H}$ & 23.0 & 26.5 & bPb-7165 & Near peak marker for $6 \mathrm{H} \mathrm{QTL}^{\mathrm{c}}$ & $\ldots$ \\
\hline $6 \mathrm{H}$ & 23.0 & 26.5 & $\mathrm{bPb}-7165$ & $\begin{array}{l}\text { Wheat BAC contig with homology to } H v-p g 4, \text { HGA-like, and } \\
\text { glycosyl-transferase genes [the same genes are part of } R p h-7 \\
\text { locus at 3HS QTL (70) }\end{array}$ & FN564434.1 \\
\hline $6 \mathrm{H}$ & $\ldots$ & 28.4 & cMWG652A & Barley catalase $2(99)$ & AF021939 \\
\hline $6 \mathrm{H}$ & $\ldots$ & 28.8 & bPb-6659 & Duplicate of bPb-8398 & $\ldots$ \\
\hline $6 \mathrm{H}$ & $\ldots$ & 30.8 & ksuA3b & Position of Rsp 4 from comparative mapping & $\ldots$ \\
\hline $6 \mathrm{H}$ & $\ldots$ & 33.7 & bPb-9749 & Triticum monococcum peroxidase $6(97)$ & AY857760.1 \\
\hline $6 \mathrm{H}$ & $\ldots$ & 38.0 & bPb-9807 & Barley NBS-LRR1 disease resistance protein-like protein $(79)^{\mathrm{d}}$ & FJ807681.1 \\
\hline $6 \mathrm{H}$ & $\ldots$ & 38.0 & bPb-9807 & Barley resistance gene analog S-112 (79) & AJ507088.1 \\
\hline $3 \mathrm{H}$ & $\ldots$ & 4.8 & $\mathrm{bPb}-3865$ & Maize receptor-like cytoplasmic kinase (76) & NM_001152713.1 \\
\hline $3 \mathrm{H}$ & $\ldots$ & 6.0 & bPb-7937a & Castor bean hydrolase $(88)$ & XM_002531912.1 \\
\hline $3 \mathrm{H}$ & $\cdots$ & 6.0 & bPt-1350 & $\begin{array}{l}\text { Oat receptor kinase gene cluster (80); wheat leaf rust resistance } \\
\text { kinase }(\operatorname{Lrk} 10, \operatorname{Lrk} 14, \operatorname{Lrk} 19, \text { others) }(80+)\end{array}$ & $\begin{array}{l}\text { AY083680.1; } \\
\text { U51330.1; others }\end{array}$ \\
\hline $3 \mathrm{H}$ & $\ldots$ & 10.2 & bPb-1137 & Near peak marker for $3 \mathrm{H} \mathrm{QTL}^{\mathrm{c}}$ & $\ldots$ \\
\hline $3 \mathrm{H}$ & $\ldots$ & 10.2 & bPb-1137 & Contig for barley leaf rust resistance $R p h 7$ locus (92) & AF521177.1 \\
\hline $3 \mathrm{H}$ & $\ldots$ & $\ldots$ & bPb-7965 & Complement of bPb-1137 & $\ldots$ \\
\hline $3 \mathrm{H}$ & $\ldots$ & $\ldots$ & bPb-7965 & Contig for barley leaf rust resistance $R p h 7$ locus (95) & AF521177.1 \\
\hline $3 \mathrm{H}$ & 14.1 & $\ldots$ & UMB301 & Wheat Ark and Lrk resistance genes (80) & AF085169 \\
\hline $3 \mathrm{H}$ & $\ldots$ & 30.7 & CDO395 & Linked to Rspl by comparative mapping ${ }^{\mathrm{e}}$ & $\ldots$ \\
\hline
\end{tabular}

a Chromosome.

b $\mathrm{cM}=$ centimorgans.

${ }^{c}$ Underlined notation of the position of the peak at the major $6 \mathrm{H}$ and $3 \mathrm{H}$ QTLs.

$\mathrm{d}$ NBS-LRR = nucleotide-binding site leucine-rich repeat.

e Lee and Neate $(18,19)$; Wenzl $(33)$. 
consensus map) (35). Yu et al. (34) reported a QTL on 2HL between the DArT markers bPb-0541 and bPb-5755. The peak marker for the current QTL on $2 \mathrm{HL}$ is bPb-8117 and co-maps with $\mathrm{bPb}-0541$ on the consensus map. Therefore, only the QTL on $2 \mathrm{HS}$ is believed to be unique. The SSLB resistance QTL identified in the present study at position $42.5 \mathrm{cM}$ on $2 \mathrm{HS}$ may well be part of a resistance gene cluster because leaf stripe resistance locus $D g 2$ is located at $45.8 \mathrm{cM}$ on the barley DArT consensus map (33). Bogacki et al. (3) report that SSLB, scald, and powdery mildew resistance QTLs co-locate with RFLP marker CDO370 (at $77.4 \mathrm{cM}$ ) and with HvPtr16, a defense response gene with homology to rice CBS domain-containing protein. This latter SSLB QTL was not detected in the present population, nor did we detect any effect of the Vrs 1 locus, which maps to the 92.6-cM position and is a major locus controlling row number and often having a significant influence on other traits.

Chromosome 1H QTL. The present study detected a minor QTL in the SS at peak marker bPt-0005. Lee and Neate (18) have mapped two SSLB resistance loci to the same 1HS chromosome. $R s p 2$ is estimated to be $6 \mathrm{cM}$ distal from $R s p 3$ and is tightly linked to bPb-1348. Rsp3 is flanked by bPb-3622 and bPb-6482 in the populations studied by Lee and Neate (18). However, all four DArT markers, and others linked to Rsp3, co-map to the same location at $7.2 \mathrm{cM}$ on the DArT consensus map (33). This is consistent with the earlier mapping and allelism testing of Zhong et al. (36) which failed to detect a recombinant between $R s p 2$ and $R s p 3$ among $458 \mathrm{~F}_{2}$ progeny. Therefore, the QTL on $1 \mathrm{H}$ detected in the present study would appear to correspond with one or both of the known SSLB resistance loci $R s p 2$ and $R s p 3$. Yu et al. (34) also found a major QTL at this location on their DArT map. Rsp2 has been shown to be part of a cluster which includes resistance loci for stripe rust (Rps4) (36), leaf rust (Rph4), and leaf scald (Rrs 14), and resistance QTLs for powdery mildew (Rbg-1 and Rbg-1-3) and leaf scald (Rrs-1-4 and Rrs-2) (35) and for covered smut (Ruh.q) (12) and Russian wheat aphid (25). This QTL was only detected in the SS of the present mapping population and suggests that the two CIho9831 paternal genotypes carry two different SSLB-susceptibility alleles at this resistance locus.

Cereal orthologs. Through nonhost infection studies of barley with the wheat leaf rust fungus Puccinia triticina (24), Neu et al. identified a locus (HvNR-F6) that codes for a serine-threonine kinase with high homology to the rice $\mathrm{Xa21}$ disease resistance gene. Mapping placed HvNR-F6, tightly linked to ksuA3D, in a region of barley chromosome $6 \mathrm{H}$ which is collinear with the region of rice chromosome 11 carrying $\mathrm{Xa21}$, and the two loci are tentatively identified as orthologs. The $6 \mathrm{H}$ QTL detected in the present study is also tightly linked to ksuA3D, and may be part of an orthologous cluster between barley and rice.

Duplicated resistance loci and resistance gene clusters. The DArT marker most closely linked to the peak of the 6H QTL has homology to genes which have homologs at the barley leaf rust resistance $R p h 7$ locus. It also co-maps with DArT markers having very high homology to the barley stem rust resistance gene Rpg1 and the wheat leaf rust resistance gene Lrl (Table 3). The DArT marker most closely linked to the $3 \mathrm{H}$ QTL has very high homology to the contig spanning the barley leaf rust resistance $R p h 7$ locus. In addition, the 6H QTL is near the two tightly linked and homologous RFLP marker loci ksuA3B and ksuA3D, which are most likely duplicated loci with homology to the ksuA3 probe. This probe also has homology to locus ksuA3C, which maps $\approx 20 \mathrm{cM}$ from the $3 \mathrm{H}$ QTL detected in the current study. Because the peak markers for both QTLs have homology to the same Rph7-associated genes, and because both are associated with loci homologous to the same RFLP probe, it is possible that these two QTLs are related through gene duplication. In addition, both are flanked by tightly linked markers which have homology to known disease resistance-type genes. Thus, both the $6 \mathrm{H}$ and $3 \mathrm{H}$ QTLs locate to clusters of disease resistance genes. The observation of clusters is consistent with the results of others. For example, Lee and Neate (19) identified a RAPD fragment, OPBA $12_{314 \mathrm{C}}$, as tightly linked to the Rsp3 locus on $1 \mathrm{HS}$ and used that fragment to develop a highly diagnostic STS marker. The sequence of the RAPD fragment OPBA $12_{314 \mathrm{C}}$ has $97 \%$ homology to a receptor-like kinase ARK1AS gene in barley, and such receptor-like kinase genes are associated with disease resistance in plants.

The present study has determined that resistance to SSLB in the Leger $\times$ CIho9831 DH population is conferred primarily either by having the CI allele at a major QTL on 6HS or by having the CI allele at both of two QTLs on $3 \mathrm{H}$ and $2 \mathrm{HL}$. QTLs were also detected on $2 \mathrm{HS}$ and $1 \mathrm{H}$. A variety of evidence suggests that at least the $6 \mathrm{HS}, 3 \mathrm{H}$, and $2 \mathrm{HS}$ QTLs are part of resistance gene clusters and that the 6HS and 3H QTLs may be related through duplication. The 6HS QTL is identical to or closely linked to Rsp4 and the $1 \mathrm{H}$ QTL to $R s p 2$ or $R s p 3$. The 2HL QTL corresponds to a previously reported QTL. The $3 \mathrm{H}$ and $2 \mathrm{HS}$ QTLs appear to be unique and offer new opportunities for pyramiding resistance genes through marker-assisted breeding for resistance to $S$. passerinii.

\section{ACKNOWLEDGMENTS}

We thank K. M. Ho and M. Kuc for providing the DH population; L. James, H. Gebre-Marian, L. Langille, and T. Konishi for contributing non-DArT marker genotypes; and N. Tinker for his assistance with NQTL.

\section{LITERATURE CITED}

1. Bassam, B. J., and Caetano-Anolles, G. 1993. Silver staining of DNA in polyacrylamide gels. Appl. Biochem. Biotechnol. 42:181-188.

2. Beaubien, K. A, and Smith, K. P. 2006. New SSR markers for barley derived from the EST database. Barley Genet. Newsl. 36:30-43.

3. Bogacki, P., Oldach, K. H., and Williams, K. J. 2008. Expression profiling and mapping of defence response genes associated with the barleyPyrenophora teres incompatible interaction. Mol. Plant Pathol. 9:645660.

4. Brunner, S., Keller, B., and Feuillet, C. 2003. A large rearrangement involving genes and low-copy DNA interrupts the microcollinearity between rice and barley at the Rph7 locus. Genetics 164:673-683.

5. Choo, T. M., Ho, K. M., Konishi, T., and Martin, R.A. 1992. Tests for randomness among doubled-haploid lines derived by the bulbosum method in barley (Hordeum vulgare L.). SABRAO J. 24:87-92.

6. Choo, T. M., Vigier, B., Shen, Q. Q., Martin, R. A., Ho, K. M., and Savard, M. 2004. Barley traits associated with resistance to Fusarium head blight and deoxynivalenol accumulation. Phytopathology 94:1145-1150.

7. Dellaporta, S. L., Wood, J., and Hicks, J. B. 1983. A plant minipreparation: Version II. Plant Mol. Biol. Rep. 1:19-21.

8. Fejer, S. O., Fedak, G., and Ho, K. M. 1984. Leger barley. Can. J. Plant Sci. 64:195-196

9. Fregeau-Reid, J., Choo, T.-M., Ho, K.-M., Martin, R. A., and Konishi, T. 2001. Comparisons of two-row and six-row barley for chemical composition using doubled-haploid lines. Crop Sci. 41:1737-1743.

10. Fregeau-Reid, J., Choo, T.-M., Jui, P., and Ho, K. M. 1996. Inheritance of kernel size and shape of barley. SABRAO J. 28:47-55.

11. Graner, A., Foroughi-Wehr, B., and Tekauz, A. 1996. RFLP mapping of a gene in barley conferring resistance to net blotch (Pyrenophora teres). Euphytica 91:229-234.

12. Grewel, T. S., Rossnagel, B. G., and Scoles, G. J. 2004. Mapping of covered smut resistance genes in barley (Hordeum vulgare L.). Can. J. Plant Pathol. 16:156-166.

13. Ho, K. M., Tekauz, A., Choo, T. M., and Martin, R. A. 1996. Genetic studies on net blotch resistance in a barley cross. Can. J. Plant Sci. 76:715-719.

14. Jin, Y., Steffenson, B. J., and Fetch, T. G. 1994. Sources of resistance to pathotype QCC of Puccinia graminis f. sp. tritici in barley. Crop Sci. 34:285-288.

15. Jui, P. Y., Choo, T. M., Ho, K. M., Konishi, T., and Martin, R. A. 1997. Genetic analysis of a two-row $\times$ six-row cross of barley using doubledhaploid lines. Theor. Appl. Genet. 94:549-556.

16. Lander, E. S., Green, P., Abrahamson, J., Barlow, A., Daly, M. J., Lincoln, S. E., and Newburg, L. 1987. MAPMAKER: An interactive computer package for constructing primary genetic linkage maps of experimental and natural populations. Genomics 1:174-181. 
17. Larson, S. R., Kadyrzhanova, D., McDonald, C., Sorrells, M., and Blake, T. K. 1996. Evaluation of barley chromosome-3 yield QTLs in a backcross $F_{2}$ population using STS-PCR. Theor. Appl. Genet. 93:618-625.

18. Lee, S. H., and Neate, S. M. 2007. Molecular mapping of Rsp1, Rsp2, and Rsp3 genes conferring resistance to Septoria speckled leaf blotch in barley. Phytopathology 97:155-161.

19. Lee, S. H., and Neate, S. M. 2007. Sequence tagged site markers to Rsp1, $R s p 2$, and Rsp3 genes for resistance to Septoria speckled leaf blotch in barley. Phytopathology 97:162-169.

20. Liu, Z.-W., Biyashev, R. M., and Saghai Maroof, M. A. 1996. Development of simple sequence repeat DNA markers and their integration into a barley linkage map. Theor. Appl. Genet. 93:869-876.

21. Mano, Y., and Takeda, K. 1996. Genetical studies on salt tolerance at germination in recombinant inbred, isogenic, and doubled haploid lines of barley (Hordeum vulgare L.). Bull. Res. Inst. Bioresour. Okayama Univ. 4:79-88.

22. Mathre, D. E. 1997. Compendium of Barley Diseases, 2nd ed. American Phytopathological Society, St. Paul, MN.

23. Molnar, S. J., James, L. E., and Kasha, K. J. 2000. Inheritance and RAPD tagging of multiple genes for resistance to net blotch in barley. Genome 43:224-231.

24. Neu, C., Keller, B., and Feuillet, C. 2003. Cytological and molecular analysis of the Hordeum vulgare-Puccinia triticina nonhost interaction. Mol. Plant-Microbe Interact. 16:626-633.

25. Nieto-Lopez, R. M., and Blake, T. K. 1994. Russian wheat aphid resistance in barley, inheritance and linked molecular markers. Crop Sci. 34:655-659.

26. Ramsay, L., Macaulay, M., degli Ivanissevich, S., MacLean, K., Cardle, L., Fuller, J., Edwards, K. J., Tuvesson, S., Morgante, M., Massari, A., Maestri, E., Marmiroli, N., Sjakste, T., Ganal, M., Powell, W., and Waugh, R. 2000. A simple sequence repeat-based linkage map of barley. Genetics 156:1997-2005.

27. Shtaya, M. J. Y., Marcel, T. C., Sillero, J. C., Niks, R. E., and Rubiales, D. 2006. Identification of QTLs for powdery mildew and scald resistance in barley. Euphytica 151:421-429.

28. St. Pierre, S., Gustus, C., Steffenson, B., Dill-Macky, R., and Smith, K. P. 2010. Mapping net form net blotch and Septoria speckled leaf blotch resistance loci in barley. Phytopathology 100:80-84.

29. Tinker, N. A and Mather, D. E. 1995. MQTL: Software for simplified composite interval mapping of QTL in multiple environments. J. Agric. Genomics 1:Article 2. Published with permission of CAB International. http://wheat.pw.usda.gov/jag/papers95/paper295/indexp295.html.

30. Toubia-Rahme, H., Johnston, P. A., Pickering, R. A., and Steffenson, B. J. 2003. Inheritance and chromosomal location of Septoria passerinii resistance introgressed from Hordeum bulbosum into Hordeum vulgare. Plant Breed. 122:405-409.

31. Toubia-Rahme, H., and Steffenson, B. J. 2004. Sources of resistance to Septoria speckled leaf blotch caused by Septoria passerinii in barley. Can. J. Plant Pathol. 26:358-364.

32. Vigier, B. J., Choo, T. M., and Fregeau-Reid, J. 2009. Exploring associations between agronomic and chemical composition traits for barley improvement. Cereal Res. Commun. 37:111-119.

33. Wenzl, P., Li, H., Carling, J., Zhou, M., Raman, H., Paul, E., Hearnden, P., Maier, C., Xia, L., Caig, V., Ovesna, J., Cakir, M., Poulsen, D., Wang, J., Raman, R., Smith, K. P., Muehlbauer, G. J., Chalmers, K. J., Kleinhofs, A., Huttner, E., and Kilian, A. 2006. A high-density consensus map of barley linking DArT markers to SSR, RFLP and STS loci and agricultural traits. BMC Genomics 7:206.

34. Yu, G. T., Franckowiak, S. H., Lee, S. H., Horsley, R. D., and Neate, S. M. 2010. A novel QTL for Septoria speckled leaf blotch resistance in barley (Hordeum vulgare L.) accession PI 643302 by whole-genome QTL mapping. Genome 53:630-636.

35. Yun, S. J., Gyenis, L., Hayes, P. M., Matus, I., Smith, K. P., Steffenson, B. J., and Muehlbauer, G. J. 2005. Quantitative trait loci for multiple disease resistance in wild barley. Crop Sci. 45:2563-2572.

36. Zhong, S., Toubia-Rahme, H., Steffenson, B. J., and Smith, K. P. 2006. Molecular mapping and marker-assisted selection of genes for Septoria speckled leaf blotch resistance in barley. Phytopathology 96:993-999. 